\title{
Plasma-derived exosomal pyruvate kinase isoenzyme type $M 2$ accelerates the proliferation and motility of oesophageal squamous cell carcinoma cells
}

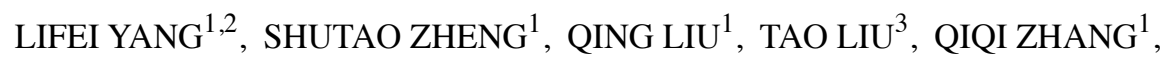 \\ XIUJUAN HAN $^{1}$, AERZIGULI TUERXUN ${ }^{1}$ and XIAOMEI LU ${ }^{1,4}$
}

${ }^{1}$ State Key Laboratory of Pathogenesis, Prevention and Treatment of High Incidence Diseases in Central Asia,

Clinical Medical Research Institute, The First Affiliated Hospital of Xinjiang Medical University,

Urumqi, Xinjiang Uygur Autonomous Region 830054; ${ }^{2}$ First Department of Lung Cancer Chemotherapy,

Cancer Hospital Affiliated with Xinjiang Medical University; ${ }^{3}$ Department of Clinical Laboratory, First Affiliated Hospital of Xinjiang Medical University; ${ }^{4}$ XinJiang Branch of Key Laboratory of Cancer Immunotherapy and Radiotherapy,

Chinese Academy of Medical Sciences, Urumqi, Xinjiang Uygur Autonomous Region 83000, P.R. China

Received March 22, 2021; Accepted June 17, 2021

DOI: $10.3892 / o r .2021 .8167$

\begin{abstract}
Exosomal pyruvate kinase isoenzyme type M2 (PKM2) has been found to play a key role in the progression of human hepatocarcinoma. However, exosomal PKM2 (especially plasma-derived exosomal PKM2), in patients with oesophageal squamous cell carcinoma (ESCC) has not been well defined. In the present study, plasma-derived exosomes were isolated from healthy controls and patients with ESCC, and identified by transmission electronic microscopy, western blotting, nano-flow cytometry, nanoparticle tracking and phagocytosis analysis; exosomal PKM2 was detected by western blotting and ELISA. In addition, changes in cellular proliferation and motility in recipient cells (Eca109) were assessed using Cell Counting Kit-8, colony formation, wound-healing and Transwell assays. The PKM2 content was higher in exosomes from patients with ESCC than in those from healthy donors. Furthermore, exosomes from patients with ESCC enhanced the proliferation and motility of ESCC cells in vitro. Notably, PKM2 was found to be transferred by exosomes, and was able to act by activating STAT3. To verify the association between PKM2 and STAT3, immunohistochemistry was employed to analyse the protein levels of PKM2 and pSTAT3 ${ }^{\text {Tyr705 }}$. These data revealed that PKM2 and
\end{abstract}

Correspondence to: Professor Xiaomei Lu, State Key Laboratory of Pathogenesis, Prevention and Treatment of High Incidence Diseases in Central Asia, Clinical Medical Research Institute, The First Affiliated Hospital of Xinjiang Medical University, 137 Liyushan South Road, Xinshi, Urumqi, Xinjiang Uygur Autonomous Region 830054, P.R. China

E-mail: luxiaomei88@163.com

Key words: oesophageal squamous cell carcinoma, exosomes, pyruvate kinase isoenzyme type M2, prognosis
pSTAT3 $3^{\text {Tyr705 }}$ were upregulated and associated with overall survival in patients with ESCC. Therefore, the present study highlights that exosomes from patients with ESCC enhance the migration and invasiveness of ESCC cells by transferring PKM2.

\section{Introduction}

Oesophageal carcinoma (EC) is the ninth most common malignancy worldwide, and its mortality rate is the sixth highest among all tumour types (1). In China, EC incidence and mortality are especially high, accounting for $\sim 50 \%$ of worldwide morbidity and mortality rates (2). As the predominant form of EC in China, oesophageal squamous cell carcinoma (ESCC) is generally associated with a poor prognosis due to inadequate effective clinical approaches for early detection (3). With or without neoadjuvant therapy or adjuvant therapy, the five-year survival rate for patients with ESCC undergoing surgery is $25-45 \%$ (4), and the infiltration and metastasis of ESCC are the primary causes of ESCC-related deaths (5). Therefore, the identification of molecular markers for predicting ESCC prognosis is crucial.

Exosomes range between $30-100 \mathrm{~nm}$ in diameter, are composed of a lipid bilayer, and are widely distributed in serum, urine, plasma and malignant ascites (6). To sustain their survival and reproduction, tumour-originated exosomes harbour oncogenic biomolecules, including RNA, DNA and proteins, that maintain internal cancer cell homeostasis. Numerous studies have documented that exosomes may also be involved in tumour progression (7). Therefore, investigation of the biological features of patients with ESCC-derived exosomes may be of great importance for the early diagnosis of ESCC, monitoring of treatment efficacy, and evaluation of their functions in tumour progression and metastasis. Pyruvate kinase isoenzyme type M2 (PKM2) is a metabolic enzyme and signalling modulator in the cytoplasm, and a transcriptional regulator in the nucleus (8). In our previous proteomics study, 
screening for exosomal differential proteins revealed that PKM2 was upregulated in patients with stage III compared with stage II ESCC. In addition, several studies indicated that PKM2 was packaged into exosomes (9-14). However, whether PKM2 can be assembled into exosomes in ESCC, and the function of exosomal PKM2 in patients with ESCC, remain unknown.

Therefore, the aim of the present study was to investigate the protein level of plasma-derived exosomal PKM2. The impacts of plasma-derived exosomes from ESCC patients on the proliferation, migration and invasion abilities of oesophageal squamous cell lines was also determined. To clarify the possible mechanism of exosomal PKM2 in ESCC, the differences in PKM2 and STAT3 mRNA expression between EC and non-malignant oesophageal tissues were analysed using the Gene Expression Profiling Interactive Analysis (GEPIA) database. In addition, the levels of PKM2 and pSTAT3 ${ }^{\text {Tyr705 }}$ in ESCC clinical samples were assessed and verified by immunohistochemistry.

\section{Materials and methods}

Patients. The present study was approved by the local ethics committee of the Affiliated Tumor Hospital of Xinjiang Medical University (approval no. K-2019054). From December 2013 to November 2014, patients with ESCC at various stages, who were hospitalized in the Cancer Hospital Affiliated with Xinjiang Medical University, were enrolled in the study. All subjects were treated by surgical dissection. The study subjects had not received surgical resection, chemotherapy or radiotherapy prior to recruitment. The TNM staging system of the American Joint Commission on Cancer (8th edition, published in 2017) was used for tumour staging (15). A cohort of 76 candidates [52 patients with ESCC, 18 healthy volunteers and 6 patients with oesophageal intraepithelial neoplasia (EIN)] who were seen in the Department of Thoracic Surgery of the Cancer Hospital Affiliated with Xinjiang Medical University (Urumqi, China) were recruited for ELISA. Detailed information on all participants is summarized in Table SI and SII; two tissue microarrays (HEso-Squ180Sur-01 and HEso-Squ180Sur-04; Shanghai Outdo Biotech Co., Ltd.) including 95 ESCC and 85 matched non-malignant control tissues, as well as a group of surgical specimens from 52 patients with ESCC (administered from the Department of Thoracic Surgery of the Cancer Hospital Affiliated with Xinjiang Medical University) were immunostained for analysis of the protein level of PKM2 and pSTAT3 ${ }^{\text {Tyr705 }}$.

Extraction of exosomes from plasma. Blood samples (4 ml) were obtained from individuals with ESCC and healthy controls prior to surgery, and were centrifuged at $4,000 \times \mathrm{g}$ for $20 \mathrm{~min}$ to remove cells and debris. The plasma was stored at $-80^{\circ} \mathrm{C}$ until required. Isolation of exosomes was performed using the exoEasy Maxi Kit (Qiagen $\mathrm{GmbH}$ ), per the manufacturers protocol. Specifically, the plasma was mixed with an equivalent volume of XBP buffer and loaded onto exoEasy spin columns. The mixture was centrifuged at $500 \mathrm{x} \mathrm{g}$ for $1 \mathrm{~min}$ at room temperature (RT). The flow-through was discarded and $10 \mathrm{ml} \mathrm{XWP} \mathrm{buffer}$ was added to each column, followed by centrifugation at $5,000 \times \mathrm{g}(5 \mathrm{~min}$ at $\mathrm{RT})$ to remove any residual buffer. After washing with XWP, the columns were transferred into new collection tubes. Buffer XE $(1 \mathrm{ml})$ was added to the membrane and incubated for $1 \mathrm{~min}$. The exosomes were collected following centrifugation at 500 and $5,000 \times \mathrm{g}$ $\left(5\right.$ min each at $\left.4^{\circ} \mathrm{C}\right)$.

Transmission electron microscopy (TEM). TEM was used to examine and photograph the exosomes. First, the exosomes were isolated and coated onto a carbon grid as previously described (16). Briefly, exosome solution was dropped onto 100 -mesh sample-loaded copper mesh and fixed with $2 \%$ glutaraldehyde and $2 \%$ paraformaldehyde in $0.1 \mathrm{~mol} / 1$ sodium cacodylate buffer at $\mathrm{pH} 7.3$ for $3 \mathrm{~h}$ at RT. Afterwards, the grids were air dried and the exosome morphology photographed using a transmission electron microscope (Tecnai ${ }^{\mathrm{TM}} \mathrm{G} 2$ spirit Bio-Twin; FEI; Thermo Fisher Scientific, Inc.) at an acceleration voltage of $100 \mathrm{kV}$. Digital images were captured with a charge-coupled device camera (Veleta; Olympus Soft Imaging Solutions $\mathrm{GmbH}$ ).

Exosome size and concentration analysis. A volume of $5 \mu 1$ exosomes was diluted in PBS to $30 \mu \mathrm{l}$. After the standard sample was tested, the exosome sample was loaded. Information regarding the size and concentration of exosomes was detected and analysed using Nano flow cytometry (NanoFCM) (instrumentation, Flow NanoAnalyzer; NanoFCM) as previously described (17).

NanoFCM analysis of exosomes-bound beads. A volume of $10 \mu 1$ exosomes was diluted to $0.2 \mu \mathrm{g} / \mu 1$. Then, $20 \mu 1$ FITC mouse anti-human CD9 (cat. no. 555371; BD Biosciences), FITC mouse anti-human CD81 (cat. no. 551108; BD Biosciences) and FITC mouse IgG (cat. no. 400108, BioLegend, Inc.) was added. The sample was incubated at $37^{\circ} \mathrm{C}$ for $30 \mathrm{~min}$ in the dark, and rinsed twice with PBS by ultracentrifugation at $100,000 \mathrm{xg}$ $\left(2 \mathrm{~h}\right.$ at $\left.4^{\circ} \mathrm{C}\right)$. The pellet was subsequently resuspended in $100 \mu 1$ PBS for detection and analysis using NanoFCM. Instrumentation; Flow NanoAnalyzer; NanoFCM (Flow NanoAnalyzer, Model No: N30E, S/N: FNAN30E2007151114; Software:V1.08).

Cell culture. Eca109, KYSE30, KYSE150, TE-1 and KYSE510 cells were purchased from Wuhan University, China, and maintained in RPMI-1640 medium (HyClone; Cytiva) enriched with 10\% FBS (Shanghai VivaCell Biosciences, Ltd.) and penicillin-streptomycin (HyClone; Cytiva) in a humidified atmosphere containing $5 \% \mathrm{CO}_{2}$ at $37^{\circ} \mathrm{C}$.

Uptake of exosomes by Eca109 cells. To determine whether Eca109 cells could take up exosomes from patients with ESCC, the PKH67 Green Fluorescent Cell Linker Kit (Sigma-Aldrich; Merck KGaA) was used to label exosomes, according to the manufacturers protocol. Briefly, ESCC patient exosomes were diluted and resuspended in sterile PBS to a final concentration of $50 \mu \mathrm{g} / \mathrm{ml}$. Diluent C (250 $\mu \mathrm{l}$; PKH67 solution) was added to $1.6 \mu 1$ PKH67 dye, and $200 \mu \mathrm{l}$ exosomes were mixed with $250 \mu$ PKH67 solution in a $1.5-\mathrm{ml}$ microfuge tube. The samples were gently mixed for $4 \mathrm{~min}$ at $37^{\circ} \mathrm{C}$, and $500 \mu 11 \%$ BSA was added to bind the excess PKH67 dye. Next, the ExoEasy Maxi Kit was 
used to collect PKH67-labelled exosomes, after which the PKH67-labelled exosomes were resuspended in RPMI-1640. Eca109 cells were seeded onto culture dishes $(35-\mathrm{mm}$ diameter) at a density of $3 \times 10^{5}$ cells/dish, and incubated in complete medium for $24 \mathrm{~h}$ at $37^{\circ} \mathrm{C}\left(5 \% \mathrm{CO}_{2}\right)$. Subsequently, the plates were rinsed three times with PBS to remove the effect of serum exosomes, and medium containing $100 \mu \mathrm{l}$ PKH67-labelled exosomes and an equivalent volume of the PKH67-PBS or PBS control, was added to the appropriate wells. After that, cells and ESCC exosomes were co-cultured for 1, 2, 4 and $24 \mathrm{~h}$, after which the dishes were gently rinsed in PBS and fixed with $4 \%$ paraformaldehyde solution for $30 \mathrm{~min}$ at RT. The dishes were then rinsed again three times using PBS. After nuclear staining was performed using ProLong Gold Antifade Reagent with DAPI (Beijing Solarbio Science \& Technology Co., Ltd.), the dishes were viewed under a fluorescence microscope.

ELISA. The PKM2 ELISA kit (cat. no. tw041272; Shanghai Tongwei Biological Technology Co., Ltd.) was equilibrated at RT for 60 min. Plasma was completely lysed in a water bath set at $37^{\circ}$ for $30 \mathrm{~min}$. After standing at RT for $30 \mathrm{~min}$, the supernatant was obtained. For sample addition, $50 \mu \mathrm{l}$ standard or $10 \mu \mathrm{l}$ sample mixed with $40 \mu \mathrm{l}$ sample diluent was added to each ELISA plate well, and $100 \mu$ l biotin-conjugated antibody working solution was added to all wells, followed by incubation for $1 \mathrm{~h}$ at $37^{\circ} \mathrm{C}$. The supernatant was discarded, and the plate was rinsed five times with wash solution (in the kit). Then, $50 \mu \mathrm{l}$ each of substrate solution $\mathrm{A}$ and $\mathrm{B}$ was added to each well, followed by incubation at $37^{\circ} \mathrm{C}$ in the dark for $15 \mathrm{~min}$. Then, $50 \mu \mathrm{l}$ stop solution was added to terminate the reaction, and 5 min later, the OD value of each well was determined using a microplate reader set at $450 \mathrm{~nm}$. A standard curve of the OD values was plotted by using GraphPad Prism 5.0 software (GraphPad Software, Inc.), and the concentration of plasma-derived PKM2 in each sample was determined.

Cellular proliferation assay. Eca109 cells were washed with PBS and seeded into 96-well plates (3,000 cells/well) in RPMI-1640 medium enriched with $10 \%$ exosome-free FBS, with or without exosomes $(50 \mu \mathrm{g} / \mathrm{ml})$. After incubation for $2 \mathrm{~h}$, the Cell Counting Kit 8 (APExBIO Technology LLC) was used to assess proliferative capacity after $0,24,48,72$ and $96 \mathrm{~h}$ according to the product instructions.

Transwell invasion assay. Diluted Matrigel (60 $\mu \mathrm{l})$ was added to the upper compartment of the Transwell plates (Corning, Inc.) and incubated at $37^{\circ} \mathrm{C}$ for $2 \mathrm{~h}$. Subsequently, $5 \times 10^{3}$ Eca109 cells were added into the upper compartment in medium without or with exosomes $(50 \mu \mathrm{g} / \mathrm{ml}) ; 500 \mu \mathrm{l}$ medium with $10 \%$ exosome-free FBS was added to the lower compartment and incubated, and the plate was incubated for $24 \mathrm{~h}$. The cells were then fixed with $4 \%$ paraformaldehyde at $4{ }^{\circ} \mathrm{C}$ for $30 \mathrm{~min}$, followed by staining with crystal violet (Beijing Solarbio Science \& Technology Co., Ltd.) at RT for $5 \mathrm{~min}$. The migrated cells were counted and photographed using an inverted phase-contrast microscope.

Wound-healing assay. Eca109 Cells were seeded into a 6-well flat-bottomed plate $\left(1 \times 10^{5} /\right.$ well) in RPMI 1640 medium enriched with $10 \%$ exosome-free FBS as previously described (18). Subsequently, a pipette tip was used to create a wound in the cell monolayer, the floating cells were removed, and medium without or with $50 \mu \mathrm{g} / \mathrm{ml}$ exosomes was added to each well. Thereafter, an inverted microscope was used to capture images at 0 and $24 \mathrm{~h}$ post-scratching. The motility of cells was determined by comparing the closure distance between the two time points.

Colony formation assay. Eca109 cells were plated into 6-well plates $\left(1 \times 10^{3}\right.$ per well) in RPMI 1640 medium with $30 \%$ exosome-free FBS, with or without exosomes $(50 \mu \mathrm{g} / \mathrm{ml})$. The plates were incubated at $37^{\circ} \mathrm{C}$ with $5 \% \mathrm{CO}_{2}$ for $10-14$ days. Formed colonies were fixed with $4 \%$ paraformaldehyde at $4^{\circ} \mathrm{C}$ for $30 \mathrm{~min}$, stained with crystal violet for $15 \mathrm{~min}$ at RT and washed with distilled water. Colonies containing $>50$ cells were counted by eye.

Western blotting. Total protein from the exosomal, cell or co-culture cell samples was extracted using RIPA lysis buffer (Beijing Solarbio Science \& Technology Co., Ltd.), and the concentration was calculated using a BCA kit. The proteins were boiled at $100^{\circ} \mathrm{C}$ for $5 \mathrm{~min}$, fractionated on $10 \%$ SDS-PAGE gels for $120 \mathrm{~min}$, and then blotted onto a PVDF membrane for $100 \mathrm{~min}$. Thereafter, 5\% skimmed milk was used to block the membranes for $2 \mathrm{~h}$ at RT, followed by inoculation with antibodies against CD9 (1:1,000; cat. no. 20597-1-AP; ProteinTech Group, Inc.), CD63 (1:1,000; cat. no. 25682-1-AP; ProteinTech Group, Inc.), CD81 (1:1,000; cat. no. 27855-1-AP; ProteinTech Group, Inc.), TSG101 (1:1,000; cat. no. 14497-1-AP; ProteinTech Group, Inc.), PKM2 (1:1,000; cat. no. 15822-1-AP; ProteinTech Group, Inc.), STAT3 (1:1,1000; cat. no. 10253-2-AP; ProteinTech Group, Inc.), pSTAT3 ${ }^{\text {Tyr705 }}$ (1:1,000; cat. no. 9145S; Cell Signaling Technology, Inc.) and GAPDH (1:10,000; cat. no. ab8245; Abcam) at $4^{\circ} \mathrm{C}$ overnight. Then, the membranes were incubated with secondary goat anti-mouse IgG antibody $(1: 1,000$; cat. no. BA1010) and goat anti-rabbit IgG antibody (1:1,000, cat. no. BA1011) (both Wuhan Boster Biological Technology, Ltd.) at RT for $60 \mathrm{~min}$. Finally, the membranes were rinsed three times with PBST (PBS + $0.05 \%$ Tween 20 ), followed by soaking in AP Chromogenic Substrate (Invitrogen; Thermo Fisher Scientific, Inc.) for signal development. Grayscale quantification was performed using ImageJ software $(1.51 \mathrm{j} 8$, National Institutes of Health).

Immunofluorescence analysis. A total of $4 \times 10^{5}$ Eca109 cells were inoculated into a 35-mm petri dish with RPMI 1640 medium supplemented with $10 \%$ exosome-free FBS, with or without exosomes $(50 \mu \mathrm{g} / \mathrm{ml})$, and incubated for $24 \mathrm{~h}$. The cells were then fixed with $4 \%$ paraformaldehyde at RT for $30 \mathrm{~min}$, and then treated with $0.5 \%$ Triton X-100 diluted with PBS at RT for $15 \mathrm{~min}$. Cells were incubated with antibodies specific for PKM2 (1:40; cat. no. 15822-1 AP; ProteinTech Group, Inc.) and pSTAT3 ${ }^{\text {Tyr705 }}$ (1:150, cat. no. 9145S, Cell Signaling Technology) overnight at $4^{\circ} \mathrm{C}$, and then with Alexa Fluor-labelled secondary antibodies (1:100; cat. no. BA1142; Wuhan Boster Biological Technology, Ltd.) in the dark for $45 \mathrm{~min}$ at RT. DAPI was used to counterstain the nuclei for $20 \mathrm{~min}$ at RT, and images were captured using a laser 
scanning confocal microscope (magnification, $\mathrm{x} 400$; LSM710; Zeiss AG).

GEPIA. GEPIA (http://gepia.cancer-pku.cn/) is a widely utilized interactive web resource for plotting the expression patterns of specified genes. GEPIA contains 9,736 tumours and 8,587 non-malignant tissue samples from The Cancer Genome Atlas, as well as GTEx data resources. It is employed to conduct survival analysis on the basis of levels of specified gene expression, per the user-specified sample selections and approaches (19). Herein, GEPIA was used to determine PKM and STAT3 mRNA levels in EC, as well as subsequent correlation analyses.

Immunohistochemistry. A total of 147 ESCC and 85 non-malignant control tissues were examined. The tissue microarray and tissue samples were cut at 4- $\mu \mathrm{m}$ thickness, dewaxed, hydrated in a descending alcohol series, treated with EDTA antigen repair solution (Sigma-Aldrich; Merck KGaA) for $98^{\circ} \mathrm{C}$ for $13 \mathrm{~min}$, and then blocked in serum (OriGene Technologies, Inc.) for $1 \mathrm{~h}$ at RT. Endogenous peroxidase activity was blocked with $3 \% \mathrm{H}_{2} \mathrm{O}_{2}$. The sections were incubated overnight with rabbit anti-PKM2 (cat. no. 15822-1 AP; ProteinTech Group, Inc.) at a dilution of 1:200, and rabbit anti-pSTAT3 ${ }^{\text {Tyr705 }}$ (cat. no. 9145S, Cell Signaling Technology) at a dilution of 1:150. Then, the sections were incubated with goat anti-rabbit IgG (1:800; cat. no. 31926; Cell Signaling Technology) for $60 \mathrm{~min}$ at $37^{\circ} \mathrm{C}$. A semiquantitative scoring technique was used to determine the PKM2 and pSTAT3 ${ }^{\text {Tyr705 }}$ expression levels. An evaluation of the staining intensity and proportion of positive cells was used to assess the expression

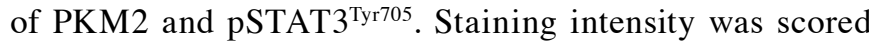
using a four-point scale as follows: 3, strong (tan); 2, medium (brown-yellow); 1 , weak (light yellow); and 0 , none. The proportion of positive cells was scored as $0,0 \% ; 1, \leq 10 \%$; $2,11-50 \% ; 3,51-75 \%$; and $4,>75 \%$ (20). The staining index (SI) was determined as the sum of the staining intensity score and the number of positive cells. Patients with ESCC were stratified into two groups on the basis of SI: i) Patients with a total score of 0-3 were clustered into the low-expression group (Fig. S1A-D); and ii) those with a total score of 3-7 were stratified into the high-expression group (21).

Statistical analysis. Numerical data are presented as the mean \pm standard deviation. Student's t-test was used to compare statistical significance between two groups, while Bonferroni's post hoc analysis was used following ANOVA. For categorical data, Fisher's exact test was used to analyse significant differences when dealing with expected values $<5$. Spearman's correlation analysis was used to analyse the correlation between the protein levels of PKM2 and pSTAT $^{\text {Tyr705 }}$. All in vitro experiments were performed 2-4 times. Survival analyses for patients with ESCC were performed using the Kaplan-Meier method, and the log-rank test was used to determine the statistical significance of the difference between the two groups. Analyses were conducted using GraphPad Prism 8.0 software (GraphPad Software) or STATA 15.0 software (StataCorp LP) at the $95 \%$ confidence level. $\mathrm{P}<0.05$ was considered to indicate a statistically significant difference.

\section{Results}

Characterization of exosomes extracted from plasma. Exosomes were successfully derived from the plasma of patients and healthy controls, and exosomes isolated from patients with ESCC were validated in terms of morphology, size and specific markers. Fig. 1A indicates that extracted exosomes from patients with ESCC appeared as discs in the TEM images. In addition, $2.84 \times 10^{9}$ vesicles were detected in most of the 1-ml plasma samples (Fig. 1B). Exosome diameter ranged from 30 to $150 \mathrm{~nm}$ based on NanoFCM analysis, and the mean diameter was $\sim 81.97 \mathrm{~nm}$ (Fig. 1C). In addition, NanoFCM displayed that the proportions of CD9 and CD81 were 7.3 and $14.5 \%$, respectively (Fig. 1D). In order to further verify exosome extraction, the expression of other exosomal proteins was confirmed by western blot analyses. The results showed that CD9, CD63, CD81 and TSG101 were expressed in exosomes (Fig. 1E). Altogether, this isolation approach was suitable for the following experiments. As shown in Fig. 1F, quantitative analysis of the western blotting data showed that the expression of exosomal PKM2 was lower in healthy subjects $($ Exo-H), than in individuals with ESCC (Exo-P) $(\mathrm{P}<0.001)$. To determine whether host cells could take up ESCC patient exosomes, PKH67 dye (green fluorescence) was used to label ESCC patient exosomes, which were then incubated with Eca109 ESCC cells in vitro. As indicated in Fig. 2A, there was no obvious phagocytosis following co-culture for $1 \mathrm{~h}$. However, the cytoplasm and nucleus exhibited green fluorescence at 2 (Fig. 2B), 4 (Fig. 2C) and 24 h (Fig. 2D) in exosomes from patients with ESCC, implying that Eca109 cells took up a significant number of exosomes compared with the PKH67-PBS control, or the PBS control. Quantification of internalized exosomes (green) showed that the average optical densities at 2 and $24 \mathrm{~h}$ were 59.67 and $50.33 \%$ of that at $4 \mathrm{~h}$, respectively. Notably, phagocytosis was the strongest at $4 \mathrm{~h}$ (Fig. 2E).

Concentration of plasma-derived PKM2 in ESCC. The aforementioned results prompted investigation into the role of exosomal PKM2 expression in patients with ESCC, which was assessed by ELISA. The clinicopathological characteristics of the plasma samples of 76 patients were acquired via diagnostic procedures, and the characteristics of ESCC, EIN and healthy donors (HDs) are summarised in Tables SI and SII. ESCC, EIN and HDs accounted for 68.4, 7.9 and $23.7 \%$, respectively. The data from patients with ESCC were extracted; 27 (51.9\%) of the 52 patients had stage II ESCC, and 25 (41.9\%) had stage III ESCC. In addition, most patients presented with T3 or T4 $(78.8 \%)$ and a positive nodal status $(61.5 \%)$.

The profile of plasma-derived PKM2 was assayed via ELISA, and the data showed that the PKM 2 content was markedly higher in patients with ESCC $(3022 \pm 528.0 \mathrm{pg} / \mathrm{ml}$ plasma $)$ and EIN patients $(2748 \pm 300.6 \mathrm{pg} / \mathrm{ml}$ plasma $)$ than in healthy controls $(2327 \pm 409.7 \mathrm{pg} / \mathrm{ml}$ serum $)(\mathrm{P}<0.001$ and $\mathrm{P}<0.05$, respectively) (Fig. 3A). No significant difference was identified in tumour grade (Fig. 3B) or lymph node stage (Fig. 3C). However, the PKM2 level of patients with stage III disease (3265 $\pm 697.9 \mathrm{pg} / \mathrm{ml}$ plasma) was markedly higher than that of patients with stage II disease $(2893 \pm 552.8 \mathrm{pg} / \mathrm{ml}$ plasma $)$ ( $\mathrm{P}<0.05$, Fig. 3D). 
A
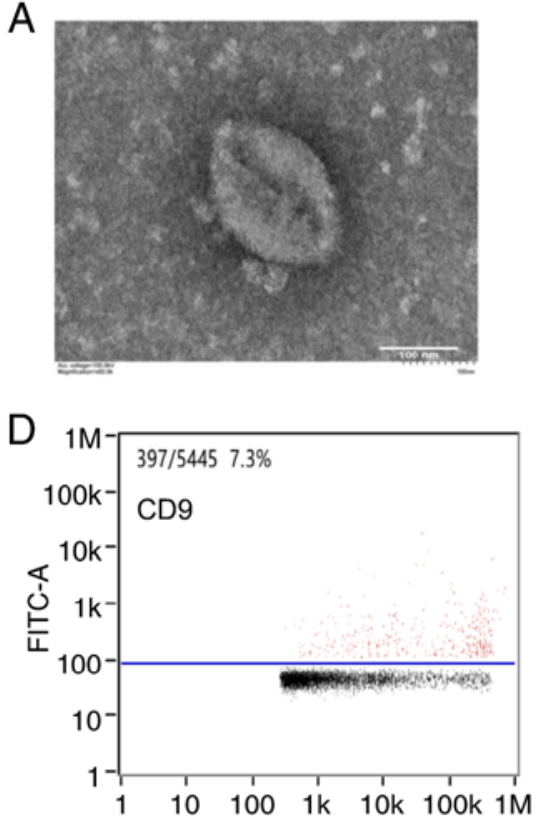

E

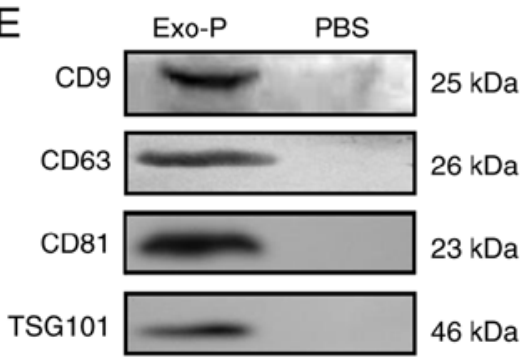

B

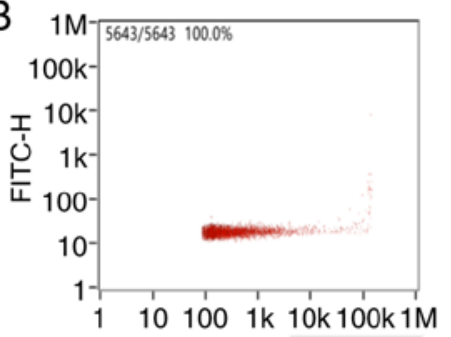

Sample concentration: $\quad 2.84 \mathrm{E}+9 \quad$ Particles $/ \mathrm{ml}$

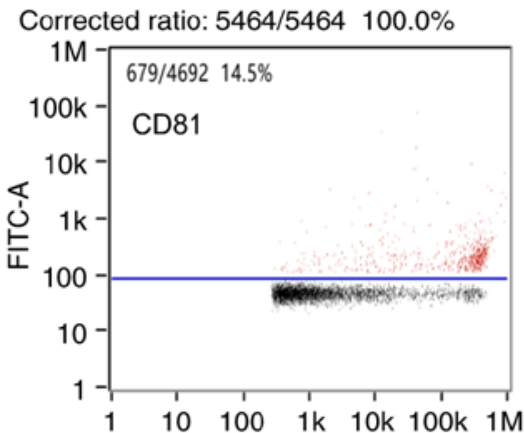

F

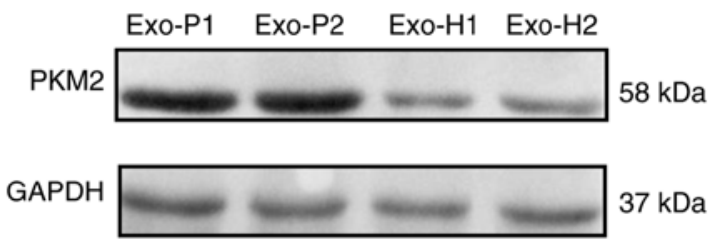

C

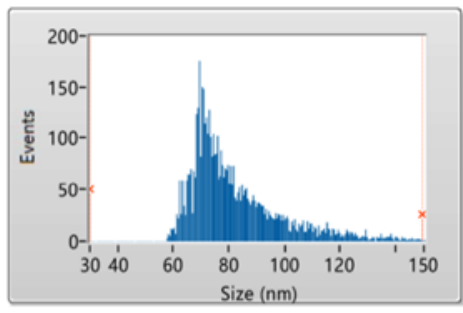

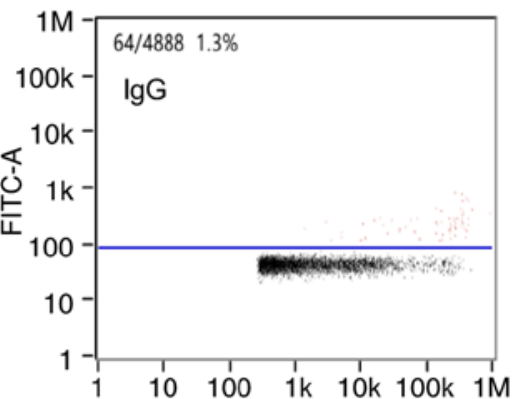

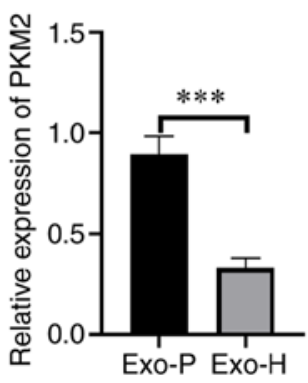

Figure 1. Characterization of plasma-derived exosomes of ESCC. (A) Exosomes isolated from patients with ESCC were observed under a transmission electron microscope to have a diameter of 50-150 nm (scale bar, $100 \mathrm{~nm}$ ). (B) Vesicles from 1- ml plasma detected by NanoFCM. (C) Size distribution of exosomes measured by NanoFCM (mean value, $81.97 \mathrm{~nm}$ ). (D) Exosome-enriched proteins, CD9 and CD81, were analysed by FCM. (E) Exosome-enriched CD9, CD63, CD81 and TSG101 were analysed by western blotting. (F) PKM2 levels in exosomes were analysed by western blotting in Exo-P and Exo-H cells. ${ }^{* * *} \mathrm{P}<0.001$. ESCC, oesophageal squamous cell carcinoma; Exo-P, exosomes from patients with ESCC; Exo-H, exosomes from healthy controls; FCM, flow cytometry; PKM2, pyruvate kinase isoenzyme type M2.

Exosomes from patients with ESCC enhance the proliferation and motility of ESCC cells, and PKM2 can be transferred by exosomes. To assess the oncogenic potential of ESCC patient-derived exosomes, the basal expression of PKM2 in a panel of ESCC cell lines was assessed by western blotting (Fig. 4A). Among these, the expression of PKM2 was the lowest in Eca109 cells. Next, Eca109 cells were treated with or without exosomes from patients with ESCC, and the colony formation assay showed that patient exosomes promoted cellular proliferation (Fig. 4B, $\mathrm{P}<0.001$ ). The CCK- 8 assay results showed that exosomes derived from patients with ESCC promoted the proliferation of ESCC cells at 24 and $48 \mathrm{~h}$, though this effect was not observed at 72 and 96 h (Fig. S1E). Although the CCK- 8 assay results suggested that exosomes had limited ability to promote proliferation, the clone formation assay revealed that exosomes promoted colony formation significantly. Thus collectively, these two experiments indicated that exosomes promoted cellular proliferation. When the mobility of recipient cells was investigated via Transwell migration assay, exosome-treated cells also exhibited elevated infiltration compared with the control cells (Fig. 4C, $\mathrm{P}<0.05$ ). Furthermore, in the wound-healing assay, patient-derived exosomes exerted increased cellular motility. At $24 \mathrm{~h}$, exosomes facilitated a higher rate of wound closure than PBS control (Fig. 4D, $\mathrm{P}<0.001$ ). Moreover, to validate that exosomes mediate PKM2 delivery and activate STAT3, Eca109 cells were exposed to exosomes from patients with ESCC and HDs, and the protein expression level of PKM2 and pSTAT3 ${ }^{\text {Tyr705 }}$ was evaluated by immunofluorescence analysis and western blotting. Quantitative analyses showed that in the ESCC-derived exosome group, PKM2 and pSTAT3 ${ }^{\text {Tyr705 }}$ expression in ESCC cells was significantly increased compared with that in the PBS group; by contrast, no significant changes in total STAT3 were observed between ESCC-derived exosome group and HDs group (Fig. 4E-I).

PKM2 mRNA expression correlates with that of STAT3 in $E C$. To verify whether PKM2 exerts its role through phosphorylation of STAT3, the mRNA levels in EC and non-malignant oesophageal tissues were examined. The findings revealed elevated mRNA levels of PKM2 and STAT3 in EC samples compared with non-malignant oesophageal tissue (Fig. S1F and G); however, no significant difference was observed. Nevertheless, there was a remarkable correlation between PKM2 and STAT3 expression in EC $(\mathrm{P}<0.05$, Fig. S1H $)$. 


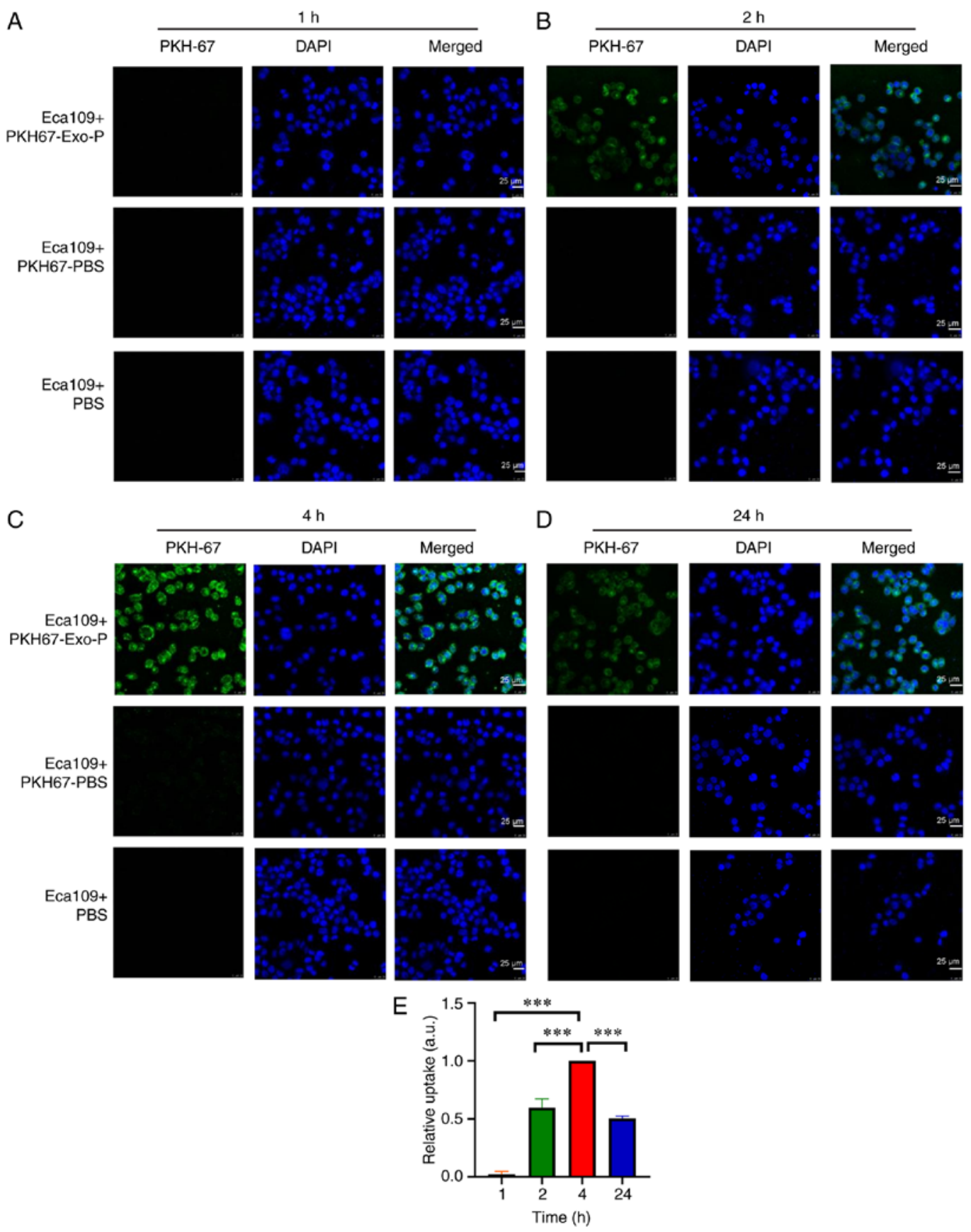

Figure 2. Laser confocal microscopy of fluorescence-labelled exosomes and exosomes taken up by Eca109 cells. Co-culture was performed for (A) 1, (B) 2, (C) 4 and (D) $24 \mathrm{~h}$. (E) Quantitative analysis of internalized exosomes (green) by Eca109 cells. Magnification, $\mathrm{x} 400$; scale bar, $25 \mu \mathrm{m} ;{ }^{* * * *} \mathrm{P}<0.001$.
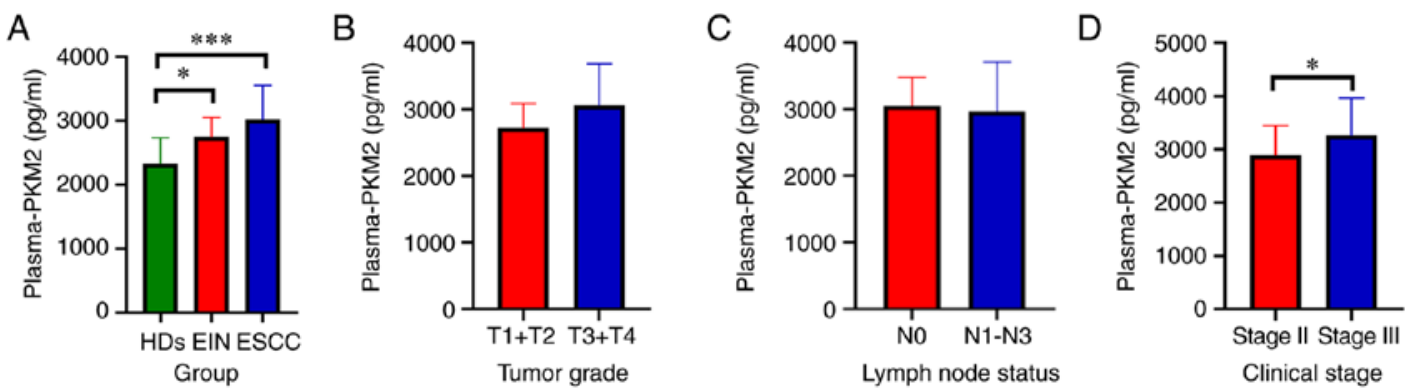

Figure 3. PKM2 is highly expressed in plasma from patients with ESCC. (A) Quantitative analysis of PKM2 levels (pg/ml plasma) in ESCC ( $=52$ ), EIN ( $\mathrm{n}=6$ ) and HDs $(\mathrm{n}=18)$. (B) Quantitative analysis of PKM2 levels (pg/ml plasma) in T1-T2 ( $\mathrm{n}=11)$ and T3-T4 $(\mathrm{n}=41)$ samples. (C) Quantitative analysis of PKM2 levels (pg/ml plasma) in N0 ( $\mathrm{n}=20)$ and N1-3 $(\mathrm{n}=32)$ samples. (D) Quantitative analysis of PKM2 levels $\left(\mathrm{pg} / \mathrm{ml}\right.$ plasma) in stage II $(\mathrm{n}=27)$ and stage III $(\mathrm{n}=25) .{ }^{*} \mathrm{P}<0.05$ and ${ }^{* * *} \mathrm{P}<0.001$. PKM2, pyruvate kinase isoenzyme type M2; ESCC, oesophageal squamous cell carcinoma; EIN, oesophageal intraepithelial neoplasia; HDs, healthy donors. 
A

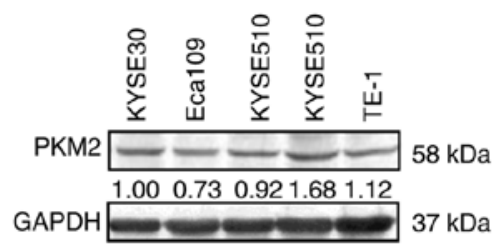

B

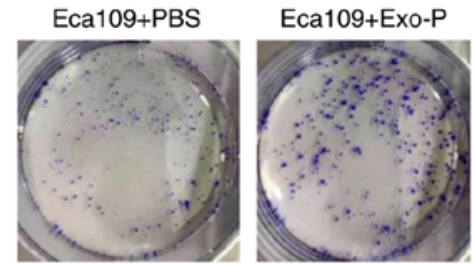

D

C
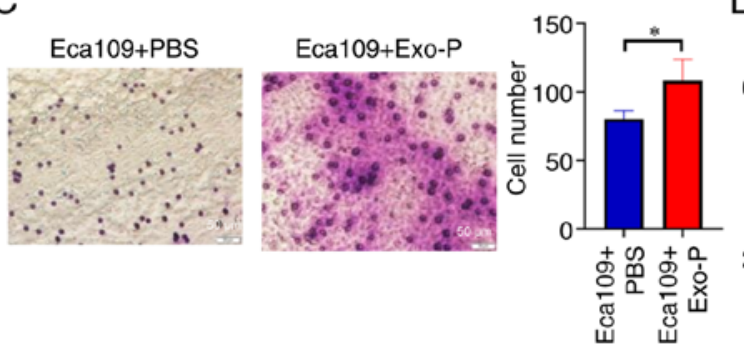

E
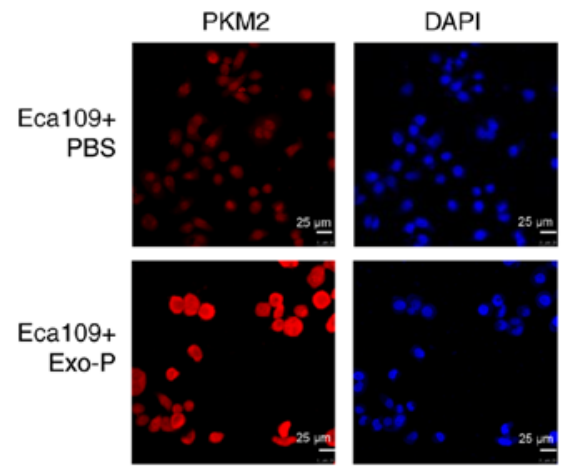

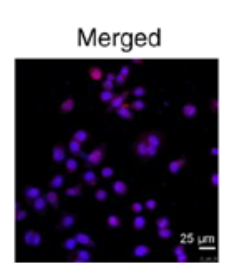

F
Eca109+Exo-P

Eca109+PBS

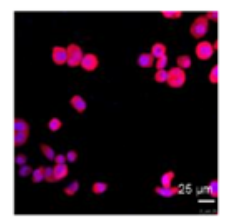

$C_{25}=\underline{x}$
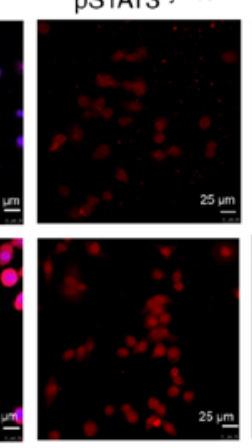
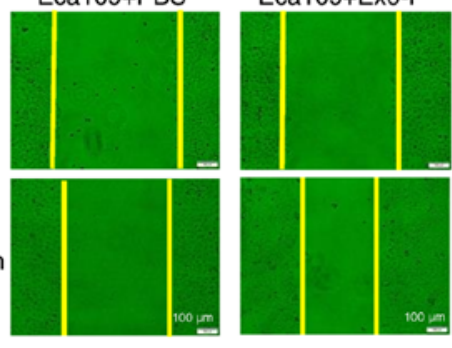

F
G

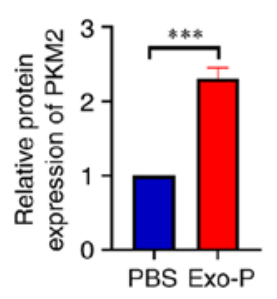

I
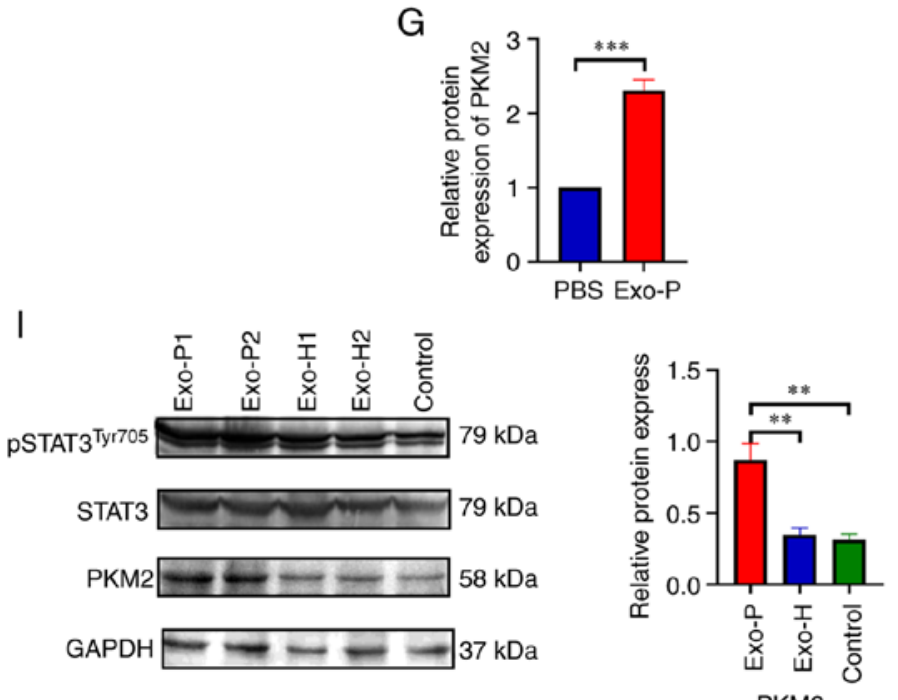

$\mathrm{H}$

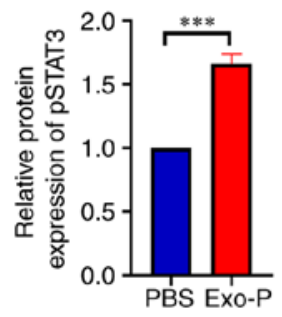

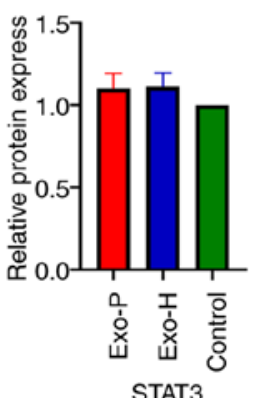

STAT3
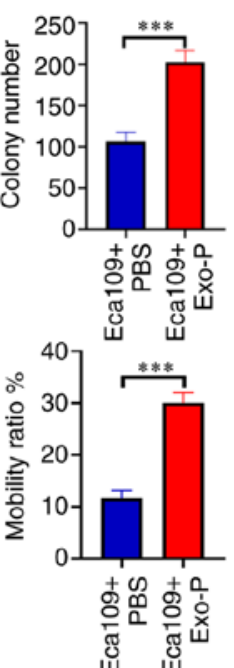

DAPI
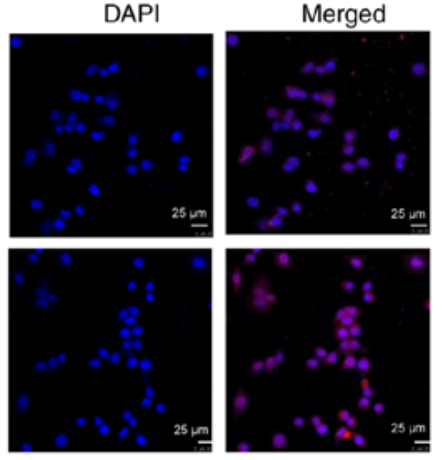

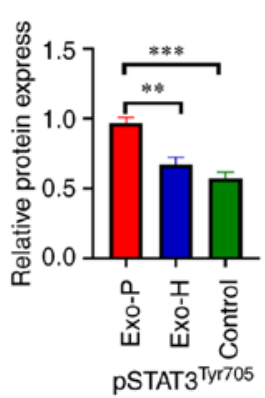

Figure 4. Exosomes affect the proliferation, migration and invasiveness of recipient Eca109 cells after co-cultivation for $24 \mathrm{~h}$. (A) Endogenous expression of PKM2 in ESCC cell lines. (B) Proliferation of recipient Eca109 cells with PBS or Exo-P was assessed using the colony formation method. (C) Invasiveness of Eca109 cells with PBS or Exo-P was assessed by Transwell assay. (D) Migration of Eca109 cells treated with PBS or Exo-P was assessed using the wound-healing method. (E) PKM2 protein level of recipient Eca109 cells treated with PBS or Exo-P was analysed by immunofluorescence analysis. Magnification, x400; scale bar, $25 \mu \mathrm{m}$. (F) pSTAT3 ${ }^{\mathrm{Ty} 705}$ protein of recipient Eca109 cells with PBS or Exo-P was analysed by immunofluorescence analysis. Magnification, $\mathrm{x} 400$; scale bar, $25 \mu \mathrm{m}$. Quantification of immunofluorescence of (G) PKM2 and (H) pSTAT3 ${ }^{\text {Tyr705 }}$ levels in Eca109 cells. (I) PKM2, total STAT3 and pSTAT3 3 Tyr705 protein levels of recipient Eca109 cells treated with Exo-P and Exo-H were analysed by western blotting. ${ }^{*} \mathrm{P}<0.05,{ }^{* *} \mathrm{P}<0.01$ and ${ }^{* * * *} \mathrm{P}<0.001$. ESCC, oesophageal squamous cell carcinoma; Exo-P, Exosomes from patients with ESCC. PKM2, pyruvate kinase isoenzyme type M2; Exo-H, Exosomes from healthy controls.

PKM2 and pSTAT3 ${ }^{T y r 705}$ are associated with clinicopathological features and prognosis in patients with ESCC. Tissue microarrays and 52 ESCC tumour tissues obtained from diagnostic procedures were immunostained for PKM2 and $\mathrm{pSTAT} 3^{\mathrm{Ty} 705}$. To validate the correlation between PKM2 and pSTAT3 ${ }^{\mathrm{Ty} 705}$, their protein levels were detected by immunohistochemical analysis. As ESCC showed increased PKM2 expression and pSTAT $^{\text {Tyr705 }}{ }^{\text {compared with normal-adjacent }}$ 
A

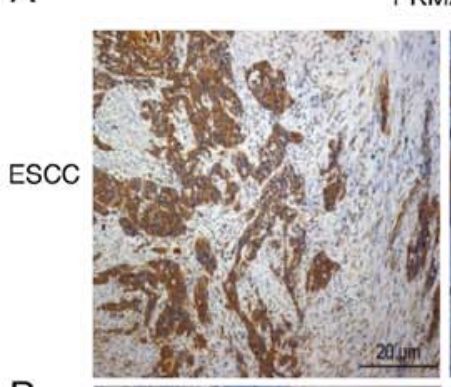

B

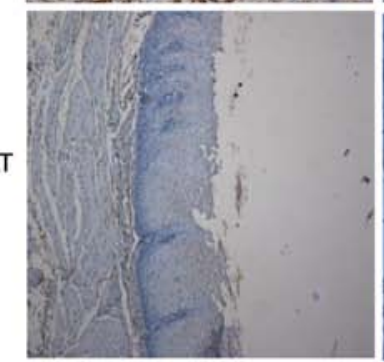

C

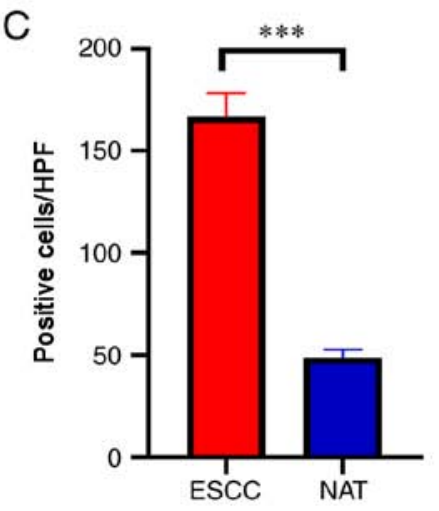

D

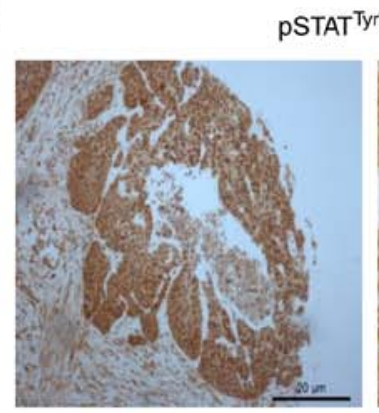

E
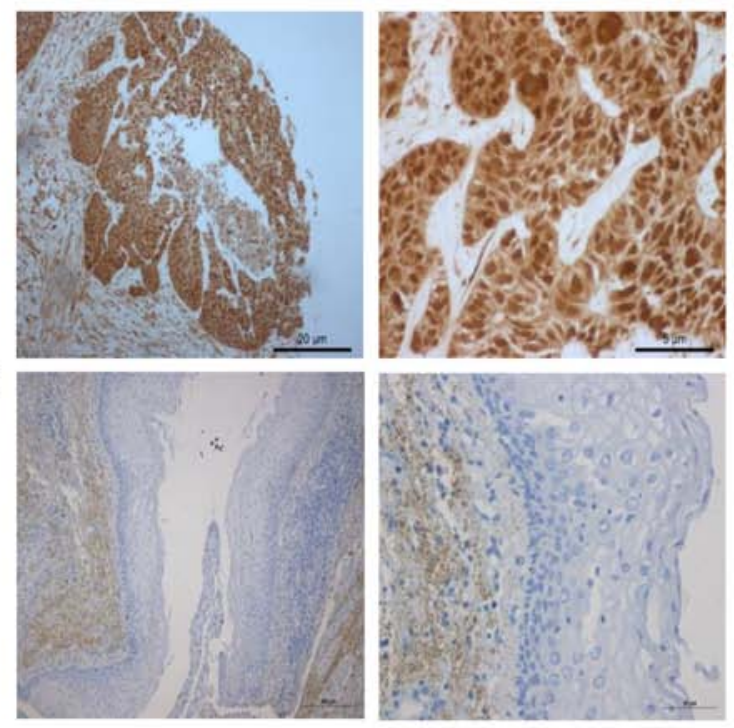

$\mathrm{F}$

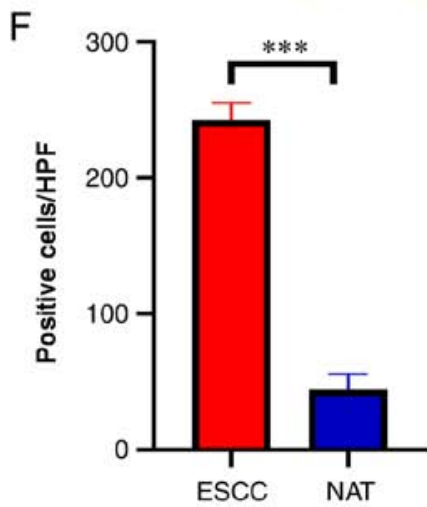

Figure 5. PKM2 and pSTAT3 ${ }^{\text {Tyr705 }}$ is highly expressed in ESCC tissues. Representative images of immunohistochemical staining of PKM2 in (A) ESCC and (B) matched NAT. (C) Quantitative analyses of immunohistochemical PKM2 data. Representative images of the immunohistochemical staining of

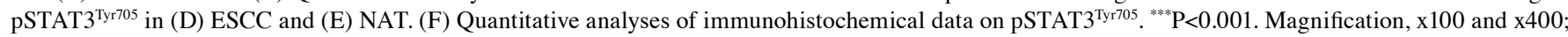
scale bar, 20 and $5 \mu \mathrm{m}$, respectively. ESCC, oesophageal squamous cell carcinoma; PKM2, pyruvate kinase isoenzyme type M2; HPF, high power field; NAT, normal-adjacent tissue.

tissues (Fig. 5A-F), further assays to assess the clinicopathological potential of PKM2 and pSTAT3 ${ }^{\text {Tyr705 }}$ in ESCC were performed. The PKM2 expression level was positively linked to metastasis to the lymph nodes $\left(\chi^{2}=8.200 ; \mathrm{P}=0.004\right.$; Table I), TNM stage $\left(\chi^{2}=7.718 ; \mathrm{P}=0.022\right.$; Table $\left.\mathrm{I}\right)$, and the upregulation of pSTAT3 $3^{\text {Tyr705 }}$ was associated with TNM stage $\left(\chi^{2}=7.408\right.$; $\mathrm{P}=0.006$; Table II).

The Kaplan-Meier survival curve showed that the median OS of ESCC patients with high and low PKM2 expression was 20.3 and 49.1 months, respectively, exhibiting a marked difference $(\mathrm{P}<0.001$; Fig. 6A). Similarly, the median OS in ESCC patients with high and low pSTAT3 ${ }^{\text {Tyr705 }}$ expression was 25.7 and 42.2 months, respectively, displaying a statistically significant difference $(\mathrm{P}<0.01$; Fig. $6 \mathrm{~B})$. After determining the risks associated with PKM2 expression and pSTAT3 ${ }^{\mathrm{Ty}}{ }^{\mathrm{y} 705}$, the 147 ESCC patients were stratified into 4 groups on the basis of

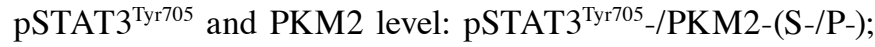

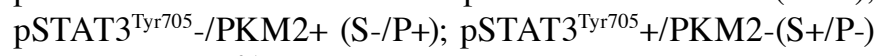
and pSTAT3 $3^{\text {Tyr705 }}+/ \mathrm{PKM} 2+(\mathrm{S}+/ \mathrm{P}+)$. Using the Kaplan-Meier approach, patients with the $\mathrm{S}+\mathrm{P}+$ expression had the shortest $\mathrm{OS}$ (17.5 \pm 1.7 months), while patients with the S-/P-expression trend had the longest $\mathrm{OS}(52.3 \pm 4.5$ months) (Fig. 6C). In addition, the relationship between PKM2 and STAT3 expression was assessed in 147 patients with ESCC. The data illustrated that PKM2 expression was markedly linked to pSTAT3 ${ }^{\text {Tyr705 }}(r=0.3503 ; \mathrm{P}<0.001$; Fig. 6D). To determine whether PKM2 or pSTAT3 $3^{\text {Tyr705 }}$ expression levels were independent of other predictive factors, univariate and multivariate analyses were conducted using a Cox multivariate proportional hazard regression model. The univariate assessment data demonstrated that PKM2 upregulation, pSTAT3 ${ }^{\mathrm{Ty} r 705}$ upregulation, male sex, lymph node metastasis, clinical classification and gross classification were predictors of poor prognosis for ESCC (Table III). Multivariate analysis showed that PKM2 expression, pSTAT3 ${ }^{\text {Tyr705 }}$ and TNM stage were independent prognostic factors of ESCC survival (Table III).

\section{Discussion}

The present study illustrated that PKM2 was assembled into exosomes; in vitro, exosomes from patients with ESCC promoted the proliferation, invasion and migration of ESCC cells. Furthermore, the results indicated that PKM2 could be transferred by exosomes, and that exosomal PKM2 may function by activating STAT3. 
Table I. Association between PKM2 expression and clinical characteristics of patients with ESCC.

\begin{tabular}{|c|c|c|c|c|c|}
\hline \multirow[b]{2}{*}{ Characteristic } & \multirow[b]{2}{*}{ Patients, N } & \multicolumn{2}{|c|}{ PKM2 expression } & \multirow[b]{2}{*}{$\chi^{2}$-value } & \multirow[b]{2}{*}{ P-value } \\
\hline & & Negative & Positive & & \\
\hline \multicolumn{6}{|l|}{ Tissue type } \\
\hline ESCC & 147 & 56 & 91 & \multirow[t]{2}{*}{29.864} & \multirow[t]{2}{*}{$0.000^{\mathrm{a}}$} \\
\hline Adjacent normal & 85 & 64 & 21 & & \\
\hline \multicolumn{6}{|l|}{ Age } \\
\hline$<60$ & 50 & 16 & 34 & \multirow[t]{2}{*}{1.194} & \multirow[t]{2}{*}{0.275} \\
\hline$\geq 60$ & 97 & 40 & 57 & & \\
\hline \multicolumn{6}{|l|}{ Sex } \\
\hline Male & 116 & 43 & 73 & \multirow[t]{2}{*}{0.246} & \multirow[t]{2}{*}{0.620} \\
\hline Female & 31 & 13 & 18 & & \\
\hline \multicolumn{6}{|l|}{ T stage } \\
\hline $\mathrm{T} 1-\mathrm{T} 2$ & 33 & 10 & 23 & \multirow[t]{2}{*}{1.096} & \multirow[t]{2}{*}{0.295} \\
\hline $\mathrm{T} 3-\mathrm{T} 4$ & 114 & 46 & 68 & & \\
\hline \multicolumn{6}{|l|}{$\mathrm{N}$ stage } \\
\hline N0-N1 & 75 & 37 & 38 & \multirow[t]{2}{*}{8.200} & \multirow[t]{2}{*}{$0.004^{\mathrm{a}}$} \\
\hline $\mathrm{N} 2-\mathrm{N} 3$ & 72 & 19 & 53 & & \\
\hline \multicolumn{6}{|l|}{ TNM stage } \\
\hline I & 8 & 3 & 5 & \multirow[t]{3}{*}{7.718} & \multirow[t]{3}{*}{$0.022^{\mathrm{a}}$} \\
\hline II & 71 & 35 & 36 & & \\
\hline III & 68 & 18 & 50 & & \\
\hline \multicolumn{6}{|c|}{ Differentiation degree } \\
\hline Well & 10 & 4 & 6 & \multirow[t]{3}{*}{1.992} & \multirow[t]{3}{*}{0.681} \\
\hline Moderate & 99 & 34 & 65 & & \\
\hline Poor & 38 & 18 & 20 & & \\
\hline \multicolumn{6}{|l|}{ Gross classification } \\
\hline Ulcerative type & 85 & 34 & 51 & \multirow[t]{4}{*}{1.127} & \multirow[t]{4}{*}{0.749} \\
\hline Medullary type & 46 & 15 & 31 & & \\
\hline Protrude type & 7 & 4 & 3 & & \\
\hline Fungating type & 9 & 4 & 5 & & \\
\hline
\end{tabular}

ESCC, oesophageal squamous cell carcinoma. ${ }^{\mathrm{a}} \mathrm{P}<0.05$.

To the best of our knowledge, the present study was the first to investigate the biological function of exosomes in ESCC, and to establish that PKM2 can be transferred by exosomes and acts by activating STAT3. In this respect, the results have important implications for understanding the progression of ESCC.

Exosomes are extracellular vesicles found in the blood (22,23), urine (24) and other bodily fluids (25). Exosomes are secreted in excess by tumour cells under oxidative stress conditions (26), and are involved in their interaction with the cancer microenvironment (14). As core communication centres, exosomes are rich in bioactive molecules (13), including RNA, DNA and proteins. Cancer cells have been documented to produce exosomes harbouring PKM2 (14,26-28). However, whether PKM2 could be packaged and transferred in exosomes from patients with ESCC was unknown. Other studies $(29,30)$ and our previous study $(31-33)$ have shown that the expression of PKM2 in tumour tissues and cells was higher than that in normal-adjacent tissues and oesophageal epithelial cells, and that upregulation of the PKM2 isoform was associated with the increased Warburg effect of tumour cells $(34,35)$. Moreover, exosomes express blastocyte-derived surface markers (36). Cancer cells, which secrete more exosomes than normal tissue cells (37), secrete elevated levels of PKM2. In addition, seminal studies from prostate cancer (14) and liver cancer (38) have demonstrated that the elevated PKM2 in plasma exosomes of tumour patients was secreted by tumour cells. The present data were consistent with previous investigations, and verified that PKM2 was expressed by circulating exosomes of cancer patients (12). PKM2 in circulating exosomes possesses clinical significance and modulates biological roles in tumours (8). In the present study, ELISA also indicated that the plasma level of PKM2 in individuals with ESCC differed markedly to that in the healthy controls, which was in accordance with the results of a study on prostate cancer (14). 
Table II. Association between pSTAT3 ${ }^{\text {Tyr705 }}$ expression and clinical characteristics of patients with ESCC.

\begin{tabular}{|c|c|c|c|c|c|}
\hline \multirow[b]{2}{*}{ Characteristic } & \multirow[b]{2}{*}{ Patients, N } & \multicolumn{2}{|c|}{ pSTAT3 ${ }^{\text {Tyr705 }}$} & \multirow[b]{2}{*}{$\chi^{2}$-value } & \multirow[b]{2}{*}{ P-value } \\
\hline & & Negative & Positive & & \\
\hline \multicolumn{6}{|l|}{ Tissue type } \\
\hline ESCC & 147 & 57 & 90 & \multirow[t]{2}{*}{21.804} & \multirow[t]{2}{*}{$0.000^{\mathrm{a}}$} \\
\hline Adjacent normal & 85 & 60 & 25 & & \\
\hline \multicolumn{6}{|l|}{ Age } \\
\hline$\leq 60$ & 97 & 36 & 61 & \multirow[t]{2}{*}{0.332} & \multirow[t]{2}{*}{0.565} \\
\hline$>60$ & 50 & 21 & 29 & & \\
\hline \multicolumn{6}{|l|}{ Sex } \\
\hline Male & 116 & 45 & 71 & \multirow[t]{2}{*}{0.001} & \multirow[t]{2}{*}{0.993} \\
\hline Female & 31 & 12 & 19 & & \\
\hline \multicolumn{6}{|l|}{ T stage } \\
\hline $\mathrm{T} 1-\mathrm{T} 2$ & 33 & 12 & 21 & \multirow[t]{2}{*}{0.104} & \multirow[t]{2}{*}{0.747} \\
\hline T3-T4 & 114 & 45 & 69 & & \\
\hline \multicolumn{6}{|l|}{ N stage } \\
\hline N0-N1 & 75 & 34 & 41 & \multirow[t]{2}{*}{2.774} & \multirow[t]{2}{*}{0.096} \\
\hline N2-N3 & 71 & 23 & 49 & & \\
\hline \multicolumn{6}{|l|}{ TNM stage } \\
\hline I & 8 & 6 & 2 & \multirow[t]{3}{*}{7.408} & \multirow[t]{3}{*}{$0.006^{\mathrm{a}}$} \\
\hline II & 71 & 28 & 43 & & \\
\hline III & 68 & 23 & 45 & & \\
\hline \multicolumn{6}{|c|}{ Differentiation degree } \\
\hline Well & 10 & 5 & 5 & \multirow[t]{3}{*}{0.597} & \multirow[t]{3}{*}{0.540} \\
\hline Moderate & 99 & 38 & 61 & & \\
\hline Poor & 38 & 14 & 24 & & \\
\hline \multicolumn{6}{|l|}{ Gross classification } \\
\hline Ulcerative type & 85 & 33 & 52 & \multirow[t]{4}{*}{0.163} & \multirow[t]{4}{*}{0.983} \\
\hline Medullary type & 46 & 18 & 28 & & \\
\hline Protrude type & 7 & 3 & 4 & & \\
\hline Fungating type & 9 & 3 & 6 & & \\
\hline
\end{tabular}

ESCC, oesophageal squamous cell carcinoma. ${ }^{\mathrm{a}} \mathrm{P}<0.05$.

It was further confirmed that the invasion rate of ESCC cells inoculated with ESCC patient exosomes was higher than that from ESCC cells without exosomes. In the present study, although the expression level of PKM2 in plasma was not correlated with tumour grade or lymph node metastasis, it was closely associated with clinical stage. Compared with tumour grade and lymph node metastasis, clinical stage combined with these parameters may be more value in predicting the prognosis and outcome of patients. Therefore, exosomal PKM2 derived from patients with ESCC may promote proliferation and motility. This finding may provide novel insights and strategies for the averting the distant metastasis of tumours in clinical practice.

The results of the proliferation experiment in the present study were consistent with published results (39), where a blank control was used. Thus in the present study, PBS served as the mock control. Exosomes promoted cellular proliferation at 24 and $48 \mathrm{~h}$, though this effect was not observed at 72 and $96 \mathrm{~h}$. This was attributed to the following possible reasons. On one hand, the cell activity detected by CCK- 8 assays is the joint result of proliferation and apoptosis, and is the overall result from a large number of cells. Therefore, the ability to assesses cellular proliferation alone is limited. In addition, exosomes were added to the cell culture medium when the cells adhered to the well. Therefore, the result may be due to the weakened proliferation-promoting ability of exosomes after they were metabolized by cells. Although the CCK- 8 assay results suggested that exosomes had limited ability to promote proliferation, the clone formation assay revealed that exosomes significantly colony formation, which focuses on the proliferation ability of single cells, crucial for subsequent colony formation. The combined results of these two experiments indicated that exosomes promoted cellular proliferation.

When examining the basal expression of PKM2, the levels were comparatively lowest in Eca109 cells. Western blotting 
A

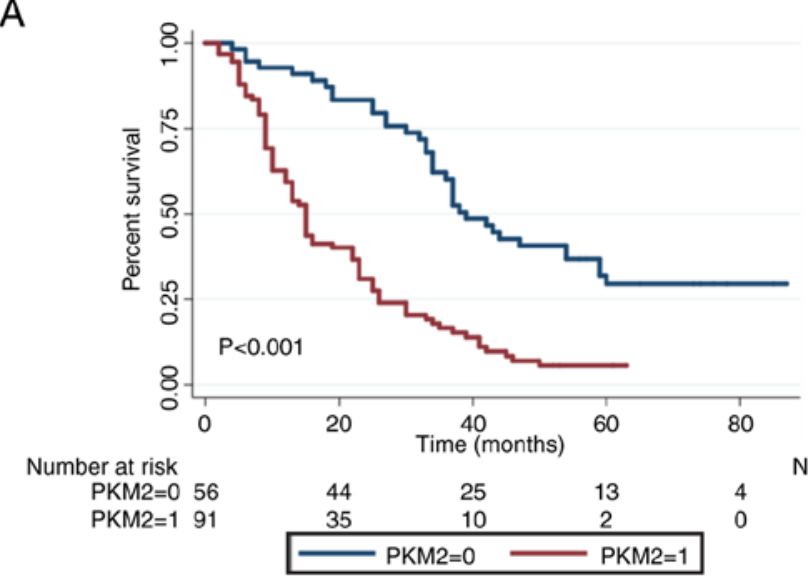

C

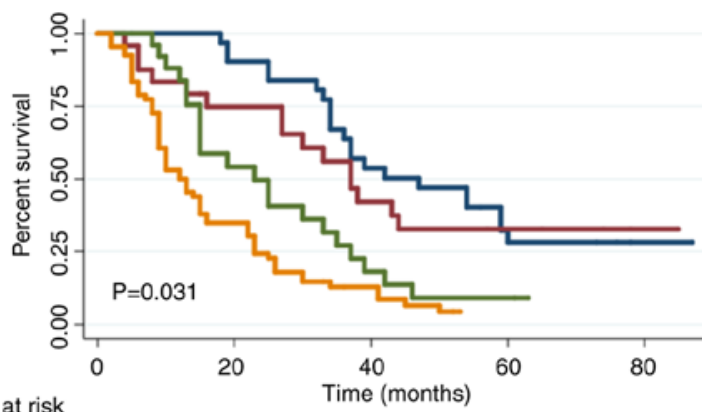

Number at risk PKM2 $=0 /$ pSTAT $3=032$ PKM2=0/pSTAT3=1 24 PKM2 $=1 /$ pSTAT3 $=025$ PKM2=1/pSTAT3 $=166$
B

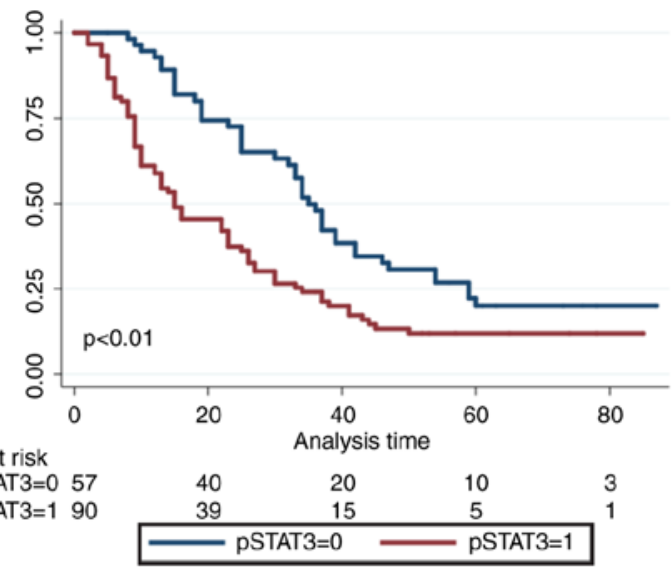

D

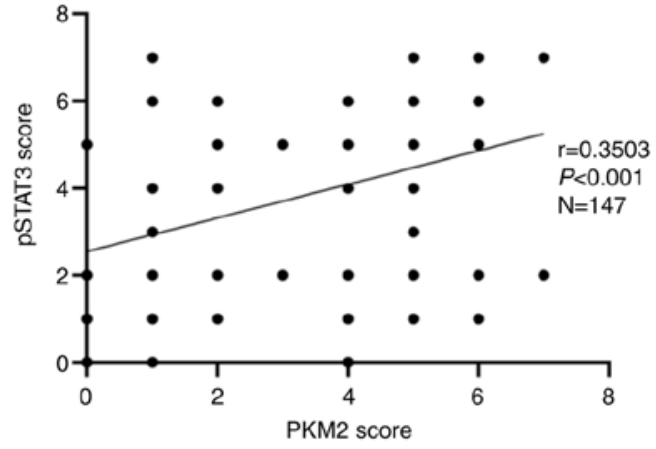

Figure 6. PKM2 and pSTAT3 ${ }^{\text {Tyr705 }}$ are associated with prognosis in patients with ESCC. (A) OS of ESCC patients with high and low PKM2 expression. 0 , low expression; 1, high expression. (B) OS of ESCC patients with high and low expression of pSTAT3. 0, low expression; 1, high expression. (C) Median OS of correlations of the expression of PKM2 combined with pSTAT3 in ESCC. (D) Correlation between PKM2 and pSTAT3 in ESCC; Spearman's correlation; $r=0.0 .3503$ and $\mathrm{P}<0.001$. pSTAT3: pSTAT3 ${ }^{\text {Tyr705 }}$. ESCC, oesophageal squamous cell carcinoma; PKM2, pyruvate kinase isoenzyme type M2; OS, overall survival.

and immunofluorescence analysis indicated that PKM2 could be packaged into and transferred by plasma-derived exosomes. Originally reported in 1934, pyruvate kinase was shown to exist as two different isoforms, PKM1 and PKM2 (40). Increaesd expression of PKM2 promotes multiple cancer cell characteristics, including extracellular signal transduction and metabolism, and is closely associated with tumorigenesis. Ma et al (27) demonstrated that exosomal PKM2 triggers a tumour-like phenotype in mesenchymal stem cells by activating glycolysis in glioma. In the current study, PKM2 was primarily expressed in the cytoplasm, and occasionally in the nucleus in the high-expression group, while in patients in the low-expression group, PKM2 was almost exclusively expressed in the cytoplasm. According to the follow-up results, the prognosis of the low-expression group was more favourable than that of the high-expression group, which indirectly confirms the prognostic value of PKM2. Furthermore, 91 patients had high PKM2 expression, and 56 patients had low PKM2 expression. According to previous studies, the positive expression rate of PKM2 in solid tumours is $20-70 \%(29,41,42)$, which is consistent with the present study. However, it was slightly higher than in our previous study (31). The possible reasons are as follows: i) the results of immunohistochemical staining were quantitatively analysed; and ii) scores $\leq 3$ were included in the low-expression group.

Western blotting and immunofluorescence analysis suggested that pSTAT3 ${ }^{\text {Tyr705 }}$ was increased in co-cultured cells. STAT3 is widely expressed in various tissues and cell types, where it participates in the regulation of physiological functions including cellular differentiation, proliferation, malignant transformation and apoptosis inhibition. Overexpression of STAT3 can result in abnormal cellular proliferation and inhibition of apoptosis (43), and several studies have revealed that PKM2 regulation of STAT3 expression is associated with cancer cell migration and invasiveness $(9,10)$. PKM2 plays a vital role in the phosphorylation of STAT3 at Tyr705, resulting in cancer cell proliferation (31). Another study using colon cancer cells demonstrated that PKM2 enhanced cellular migration via increased transcription of the STAT3 gene and the phosphorylation of STAT3 at Ser727. However, the association between PKM2 and pSTAT3 ${ }^{\mathrm{Ty} 705}$ and their prognostic value in ESCC remains unclear.

By searching the GEPIA database, it was established that the PKM mRNA expression in EC was associated with the expression level of STAT3. Tumour PKM2 and pSTAT3 ${ }^{\text {Tyr705 }}$ immunohistochemical profiles were also analysed. Similarly, 
Table III. Univariate and multivariate analysis of oesophageal squamous cell carcinoma for overall survival.

\begin{tabular}{lcccc}
\hline & \multicolumn{2}{c}{ Univariate analysis } & \multicolumn{2}{c}{ Multivariate analysis } \\
\cline { 2 - 4 } Clinical feature & P-value & $95 \%$ CI for HR & & P-value \\
\hline PKM2 & $<0.001^{\mathrm{a}}$ & $2.198-5.000$ & $<0.001^{\mathrm{a}}$ & $2.272-5.732$ \\
pSTAT3 & $0.001^{\mathrm{a}}$ & $1.341-2.874$ & $0.005^{\mathrm{a}}$ & $1.190-2.646$ \\
Sex & $0.017^{\mathrm{a}}$ & $0.235-0.894$ & 0.251 & $0.414-1.258$ \\
Age & 0.306 & $0.976-1.007$ & & 0.673 \\
T stage & 0.110 & $0.918-2.330$ & $0.003^{\mathrm{a}}$ & $0.556-2.577$ \\
N stage & $<0.001^{\mathrm{a}}$ & $1.465-4.074$ & & $1.447-2.851$ \\
TNM stage & $<0.001^{\mathrm{a}}$ & $1.874-3.713$ & & 0.126 \\
Differentiation degree & 0.842 & $0.749-1.425$ & & $0.860-3.408$ \\
Gross classification & $0.002^{\mathrm{a}}$ & $0.535-0.864$ & & \\
\hline
\end{tabular}

HR, hazard ratio. ${ }^{\mathrm{a}} \mathrm{P}<0.05$.

the expression level of PKM2 was positively correlated with the level of pSTAT $^{\text {Tyr705 }}$. High expression of PKM2 and pSTAT3 ${ }^{\text {Tyr705 }}$, or co-expression of PKM2 and pSTAT3 ${ }^{\text {Tyr705, }}$ were all associated with OS. These results suggested that STAT3 may be a critical downstream regulator of the exosomal PKM2 signalling pathway. In future studies, the exact mechanism by which exosomal PKM2 promotes tumour invasion and metastasis by activating STAT3 will be investigated.

In the current study, cells treated with PBS served as the control group. It seems somewhat far-fetched, but the selection of the control group was based on currently published literature (39). The findings of the present study suggest that patient-derived exosomes promote the malignant phenotype of ESCC cells. In future studies exploring the mechanism by which exosomal PKM2 promotes the migration and invasiveness of oesophageal squamous cells, we aim to use healthy donors as the control group. In addition, plasma levels of PKM2 in stage I patients was not included in the results, as no blood samples were collected from such patients in the sampling process. Instead, blood samples from patients with precancerous lesions were collected and analysed, namely, high-grade intraepithelial neoplasia. EIN is a necessary stage of transformation from normal oesophagus or esophagitis to ESCC. Therefore, it is reasonable to presume that the 6 cases of EIN included in the current analysis were of representative significance for the determination of PKM2 in plasma exosomes of patients with early-stage ESCC. The results suggested that exosomal PKM2 functions through STAT3. Nevertheless, the exact mechanisms remain largely unknown. The aim of further studies will be to explore the mechanism by which exosomal PKM2 promotes the migration and invasiveness of oesophageal squamous cells.

Collectively, exosomes were successfully isolated from the plasma of patients with ESCC, and were characterized for quality confirmation. ELISA indicated that exosomal PKM2 was associated with tumour stage in ESCC. In vitro cellular functional experiments also confirmed that exosomes from ESCC patient plasma promoted and accelerated cellular proliferation, invasiveness and migration. Subsequently, immunohistochemical analysis suggested that PKM2 expression was associated with the level of pSTAT3 ${ }^{\text {Tyr705 }}$. In addition, PKM2 can be transferred by exosomes. However, the identification of its function in ESCC should be further investigated in future.

\section{Acknowledgements}

The authors would like to thank Dr Adili Salai and Dr Xiaohong Sun of the Department of Thoracic Surgery of Affiliated Tumour Hospital of Xinjiang Medical University for their help with data collection.

\section{Funding}

The study was funded by the Natural Science Foundation of China (grant no. 81960527, U1603284 and 81860511), the National Innovation Research Group Cultivation Program (grant no. xyd2021C001), the Key Research and Development Project of the Xinjiang Uygur Autonomous Region (grant no. 2020B03003-1), the Science and Technology Projects of Xinjiang Uygur Autonomous Region (grant no. 2018E02067), the Tianshan Xuesong Project of the Xinjiang Uygur Autonomous Region (grant no. 2018XS19), the General Project from the State Key Laboratory of Pathogenesis, Prevention, Treatment of High Incidence Diseases in Central Asia, Urumqi, Xinjiang Uygur Autonomous Region (grant no. SKL-HIDCA-2020-11,12) and the Natural Science Foundation of Xinjiang Uygur Autonomous Region (grant no. 2020D01C218).

\section{Availability of data and materials}

The datasets used and/or analysed during the current study are available from the corresponding author on reasonable request.

\section{Authors' contributions}

LY contributed to the study design, performed the experiments, and prepared the manuscript. AT performed the cell culture, and QZ collected the clinical samples. XH carried out the ELISA. SZ interpreted the data and contributed to critical 
discussion. QL and TL analysed the experimental results and confirmed the authenticity of all the raw data. XL conceived and oversaw the whole study. All authors have read and approved the final manuscript.

\section{Ethics approval and consent to participate}

The present study was approved by the local ethics committee of the Affiliated Tumor Hospital of Xinjiang Medical University (approval no. K-2019054). All patients provided written informed consent.

\section{Patient consent for publication}

Not applicable.

\section{Competing interests}

The authors declare that they have no competing interests.

\section{References}

1. Bray F, Ferlay J, Soerjomataram I, Siegel RL, Torre LA and Jemal A: Global cancer statistics 2018: GLOBOCAN estimates of incidence and mortality worldwide for 36 cancers in 185 countries. CA Cancer J Clin 68: 394-424, 2018.

2. Zhao A, Guo L, Xu J, Zheng L, Guo Z, Ling Z, Wang L and Mao W: Identification and validation of circulating exosomes-based liquid biopsy for esophageal cancer. Cancer Med 8: 3566-3574, 2019.

3. Qin HD, Liao XY, Chen YB, Huang SY, Xue WQ, Li FF, Ge XS, Liu DQ, Cai Q, Long J, et al: Genomic characterization of esophageal squamous cell carcinoma reveals critical genes underlying tumorigenesis and poor prognosis. Am J Hum Genet 98: 709-727, 2016.

4. Zhong R, Chen Z, Mo T, Li Z and Zhang P: Potential role of circPVT1 as a proliferative factor and treatment target in esophageal carcinoma. Cancer Cell Int 19: 267, 2019.

5. Zhang W, Hong R, Li L, Wang Y, Du P, Ou Y, Zhao Z, Liu X, Xiao W, Dong D, et al: The chromosome 11q13. 3 amplification associated lymph node metastasis is driven by miR-548k through modulating tumor microenvironment. Mol Cancer 17: 125, 2018.

6. Tkach M and Théry C: Communication by extracellular vesicles: Where we are and where we need to go. Cell 164: 1226-1232, 2016.

7. Ludwig S, Floros T, Theodoraki MN, Hong CS, Jackson EK, Lang S and Whiteside TL: Suppression of lymphocyte functions by plasma exosomes correlates with disease activity in patients with head and neck cancer. Clin Cancer Res 23: 4843-4854, 2017.

8. Hsu MC and Hung WC: Pyruvate kinase M2 fuels multiple aspects of cancer cells: From cellular metabolism, transcriptional regulation to extracellular signaling. Mol Cancer 17: 35, 2018.

9. Gao X, Wang H, Yang JJ, Liu X and Liu ZR: Pyruvate kinase M2 regulates gene transcription by acting as a protein kinase. Mol Cell 45: 598-609, 2012.

10. Yang P, Li Z, Fu R, Wu H and Li Z: Pyruvate kinase M2 facilitates colon cancer cell migration via the modulation of STAT3 signalling. Cell Signal 26: 1853-1862, 2014.

11. Buschow SI, Van Balkom BW, Aalberts M, Heck AJ, Wauben M and Stoorvogel W: MHC class II-associated proteins in B-cell exosomes and potential functional implications for exosome biogenesis. Immunol Cell Biol 88: 851-856, 2010.

12. Li L, Zhang Y, Qiao J, Yang JJ and Liu ZR: Pyruvate kinase M2 in blood circulation facilitates tumor growth by promoting angiogenesis. J Biol Chem 289: 25812-25821, 2014.

13. Yang P, Li Z, Wang Y, Zhang L, Wu H and Li Z: Secreted pyruvate kinase M2 facilitates cell migration via PI3K/Akt and $\mathrm{Wnt} / \beta$-catenin pathway in colon cancer cells. Biochem Biophys Res Commun 459: 327-332, 2015.

14. Dai J, Escara-Wilke J, Keller JM, Jung Y, Taichman RS, Pienta KJ and Keller ET: Primary prostate cancer educates bone stroma through exosomal pyruvate kinase M2 to promote bone metastasis. J Exp Med 216: 2883-2899, 2019.
15. Sudo N, Ichikawa H, Muneoka Y, Hanyu T, Kano Y, Ishikawa T, Hirose Y, Miura K, Shimada Y, Nagahashi M, et al: Clinical utility of ypTNM stage grouping in the 8th edition of the American joint committee on cancer TNM staging system for esophageal squamous cell carcinoma. Ann Surg Oncol 28: 650-660, 2021.

16. Muller L, Hong CS, Stolz DB, Watkins SC and Whiteside TL: Isolation of biologically-active exosomes from human plasma. J Immunol Methods 411: 55-65, 2014.

17. Wei P, Wu F, Kang B, Sun X, Heskia F, Pachot A, Liang J and Li D: Plasma extracellular vesicles detected by single molecule array technology as a liquid biopsy for colorectal cancer. J Extracell Vesicles 9: 1809765, 2020.

18. Luo J, Liu L, Shen J, Zhou N, Feng Y, Zhang N, Sun Q and Zhu Y: MiR-576-5p promotes epithelial-to-mesenchymal transition in colorectal cancer by targeting the Wnt5a-mediated Wnt/ $\beta$-catenin signaling pathway. Mol Med Rep 23: 94, 2021

19. Tang Z, Li C, Kang B, Gao G, Li C and Zhang Z: GEPIA: A web server for cancer and normal gene expression profiling and interactive analyses. Nucleic Acids Res 45: W98-W102, 2017.

20. Yan Y, Xu Z, Huang J, Guo G, Gao M, Kim W, Zeng X, Kloeber JA, Zhu Q, Zhao F, et al: The deubiquitinase USP36 Regulates DNA replication stress and confers therapeutic resistance through PrimPol stabilization. Nucleic Acids Res 48: 12711-12726, 2020.

21. Yu S, Zhang Y, Li Q, Zhang Z, Zhao G and Xu J: CLDN6 promotes tumor progression through the YAP1-snaill axis in gastric cancer. Cell Death Dis 10: 949, 2019.

22. Zhang W, Ou X and Wu X: Proteomics profiling of plasma exosomes in epithelial ovarian cancer: A potential role in the coagulation cascade, diagnosis and prognosis. Int J Oncol 54: $1719-1733,2019$

23. Matsumoto Y, Kano M, Akutsu Y, Hanari N, Hoshino I, Murakami K, Usui A, Suito H, Takahashi M, Otsuka R, et al: Quantification of plasma exosome is a potential prognostic marker for esophageal squamous cell carcinoma. Oncol Rep 36: 2535-2543, 2016.

24. McKiernan J, Donovan MJ, O'Neill V, Bentink S, Noerholm M, Belzer S, Skog J, Kattan MW, Partin A, Andriole G, et al: A novel urine exosome gene expression assay to predict high-grade prostate cancer at initial biopsy. JAMA Oncol 2: 882-889, 2016

25. Severino V, Dumonceau JM, Delhaye M, Moll S, Annessi-Ramseyer I, Robin X, Frossard JL and Farina A: Extracellular vesicles in bile as markers of malignant biliary stenoses. Gastroenterology 153: 495-504. e8, 2017.

26. Dorayappan KDP, Wanner R, Wallbillich JJ, Saini U,Zingarelli R, Suarez AA, Cohn DE and Selvendiran K: Hypoxia-induced exosomes contribute to a more aggressive and chemoresistant ovarian cancer phenotype: A novel mechanism linking STAT3/Rab proteins. Oncogene 37: 3806-3821, 2018.

27. Ma Z, Cui X, Lu L, Chen G, Yang Y, Hu Y, Lu Y, Cao Z, Wang Y and Wang X: Exosomes from glioma cells induce a tumor-like phenotype in mesenchymal stem cells by activating glycolysis. Stem Cell Res Ther 10: 60, 2019.

28. Wei Y, Wang D, Jin F, Bian Z, Li L, Liang H, Li M, Shi L, Pan C, Zhu D, et al: Pyruvate kinase type M2 promotes tumour cell exosome release via phosphorylating synaptosome-associated protein 23. Nat Commun 8: 14041, 2017.

29. Wang C, Wang J, Chen Z, Gao Y and He J: Immunohistochemical prognostic markers of esophageal squamous cell carcinoma: A systematic review. Chin J Cancer 36: 65, 2017.

30. Xiaoyu H, Yiru Y, Shuisheng S, Keyan C, Zixing Y, Shanglin C, Yuan W, Dongming C, Wangliang Z, Xudong B and Jie M: The mTOR pathway regulates PKM2 to affect glycolysis in esophageal squamous cell carcinoma. Technol Cancer Res Treat 17: $1533033818780063,2018$.

31. Ma R, Liu Q, Zheng S, Liu T, Tan D and Lu X: PKM2-regulated STAT3 promotes esophageal squamous cell carcinoma progression via TGF- $\beta 1$-induced EMT. J Cell Biochem 2019 (Epub ahead of print).

32. Liu Q, Liang M, Liu T, Vuitton L, Zheng S, Gao X, Lu M, Li X, Sheyhidin I and Lu X: M2 isoform of pyruvate kinase (PKM2) is upregulated in Kazakh's ESCC and promotes proliferation and migration of ESCC cells. Tumour Biol 37: 2665-2672, 2016.

33. Zhang X, Liu T, Zheng S, Liu Q, Shen T, Han X, Zhang Q, Yang L and Lu X: SUMOylation of HSP27 regulates PKM2 to promote esophageal squamous cell carcinoma progression. Oncol Rep 44: 1355-1364, 2020.

34. Zhang Z, Deng X, Liu Y, Liu Y, Sun L and Chen F: PKM2, function and expression and regulation. Cell Biosci 9: 52, 2019. 
35. Li S, Huang P, Gan J, Ling X, Du X, Liao Y, Li L, Meng Y, Li Y and Bai Y: Dihydroartemisinin represses esophageal cancer glycolysis by down-regulating pyruvate kinase M2. Eur J Pharmacol 854: 232-239, 2019.

36. Song J, Sun T, Tang Z, Ruan Y, Liu K, Rao K, Lan R, Wang S, Wang T and Liu J: Exosomes derived from smooth muscle cells ameliorate diabetes-induced erectile dysfunction by inhibiting fibrosis and modulating the NO/cGMP pathway. J Cell Mol Med 24: 13289-13302, 2020.

37. Hrustincova A, Krejcik Z, Kundrat D, Szikszai K, Belickova M Pecherkova P, Klema J, Vesela J, Hruba M, Cermak J, et al: Circulating small noncoding RNAs have specific expression patterns in plasma and extracellular vesicles in myelodysplastic syndromes and are predictive of patient outcome. Cells 9: 794, 2020.

38. Hou PP, Luo LJ, Chen HZ, Chen QT, Bian XL, Wu SF, Zhou JX, Zhao WX, Liu JM, Wang XM, et al: Ectosomal PKM2 promotes $\mathrm{HCC}$ by inducing macrophage differentiation and remodeling the tumor microenvironment. Mol Cell 78: 1192-1206. e10, 2020 .
39. Tanaka Y, Kamohara H, Kinoshita K, Kurashige J, Ishimoto T, Iwatsuki M, Watanabe M and Baba H: Clinical impact of serum exosomal microRNA-21 as a clinical biomarker in human esophageal squamous cell carcinoma. Cancer 119: 1159-1167, 2013.

40. Noguchi T, Inoue H and Tanaka T: The M1-and M2-type isozymes of rat pyruvate kinase are produced from the same gene by alternative RNA splicing. J Biol Chem 261: 13807-13812, 1986.

41. $\mathrm{Wu} \mathrm{J}, \mathrm{Hu} \mathrm{L}$, Chen M, Cao W, Chen $\mathrm{H}$ and $\mathrm{He} \mathrm{T}$ : Pyruvate kinase M2 overexpression and poor prognosis in solid tumors of digestive system: Evidence from 16 cohort studies. Onco Targets Ther 9: 4277-4288, 2016.

42. Wang Y, Li Y, Jiang L, Ren X, Cheng B and Xia J: Prognostic value of glycolysis markers in head and neck squamous cell carcinoma: A meta-analysis. Aging (Albany NY) 13: 7284-7299, 2021.

43. Haura EB, Turkson J and Jove R: Mechanisms of disease: Insights into the emerging role of signal transducers and activators of transcription in cancer. Nat Clin Pract Oncol 2: 315-324, 2005.

(7) $\ominus$ This work is licensed under a Creative Commons Attribution-NonCommercial-NoDerivatives 4.0 International (CC BY-NC-ND 4.0) License. 